\title{
Erratum to: Botanical off-site and on-site data as indicators of different land use systems: a discussion with examples from Southwest Germany
}

\author{
Manfred Rösch • Angelika Kleinmann • \\ Jutta Lechterbeck · Lucia Wick
}

Published online: 16 July 2014

(c) Springer-Verlag Berlin Heidelberg 2014

Erratum to: Veget Hist Archaeobot (2014) 23 (Suppl 1):

S121-S133

\section{DOI 10.1007/s00334-014-0437-3}

Unfortunately only the upper part (ca. the last 2000 years) of the pollen diagram "Mindelsee" (Fig. 2) has been published. The whole diagram is given here.

The online version of the original article can be found under doi:10.1007/s00334-014-0437-3.

M. Rösch ( $\square) \cdot$ J. Lechterbeck

Landesamt für Denkmalpflege im Regierungspräsidium

Stuttgart, Fischersteig 9, 78343 Gaienhofen-Hemmenhofen,

Germany

e-mail: manfred.roesch@rps.bwl.de

A. Kleinmann

Ritter-Eccard-Str. 5, 88518 Herbertingen, Germany

L. Wick

IPNA, Universität Basel, Spalenring 145, 4055 Basel,

Switzerland 
О

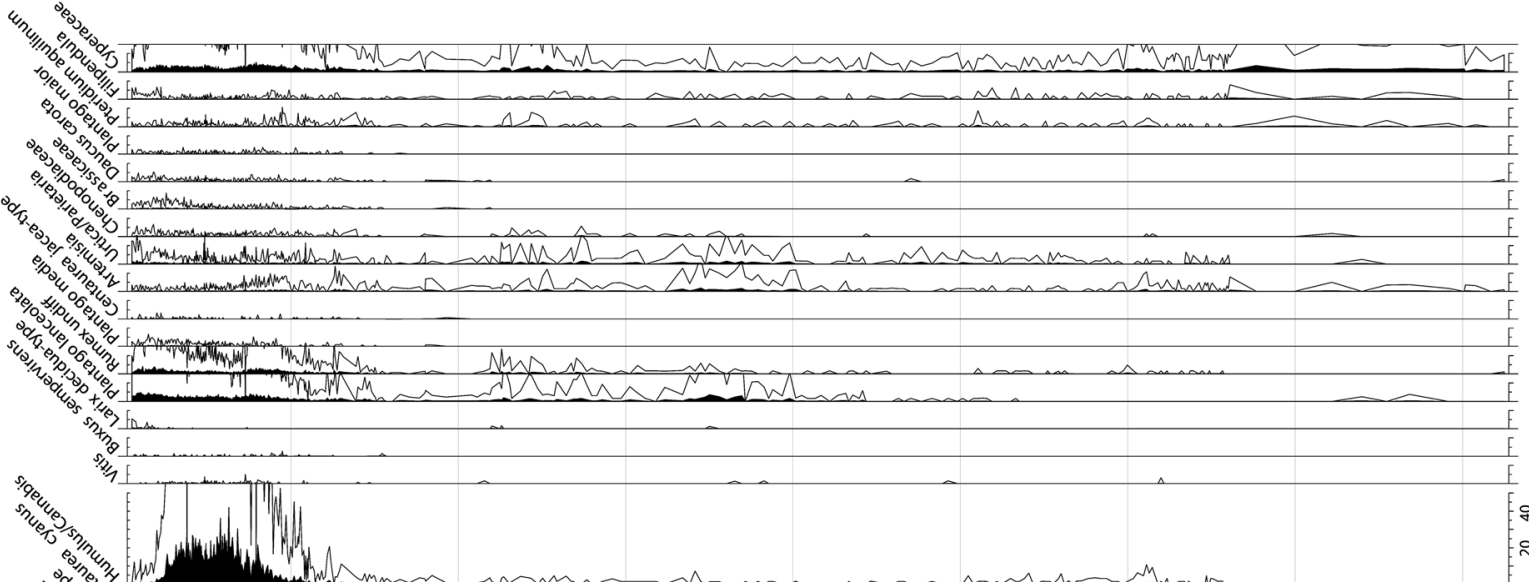

0

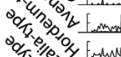

$2 \%, 4 \% 3$

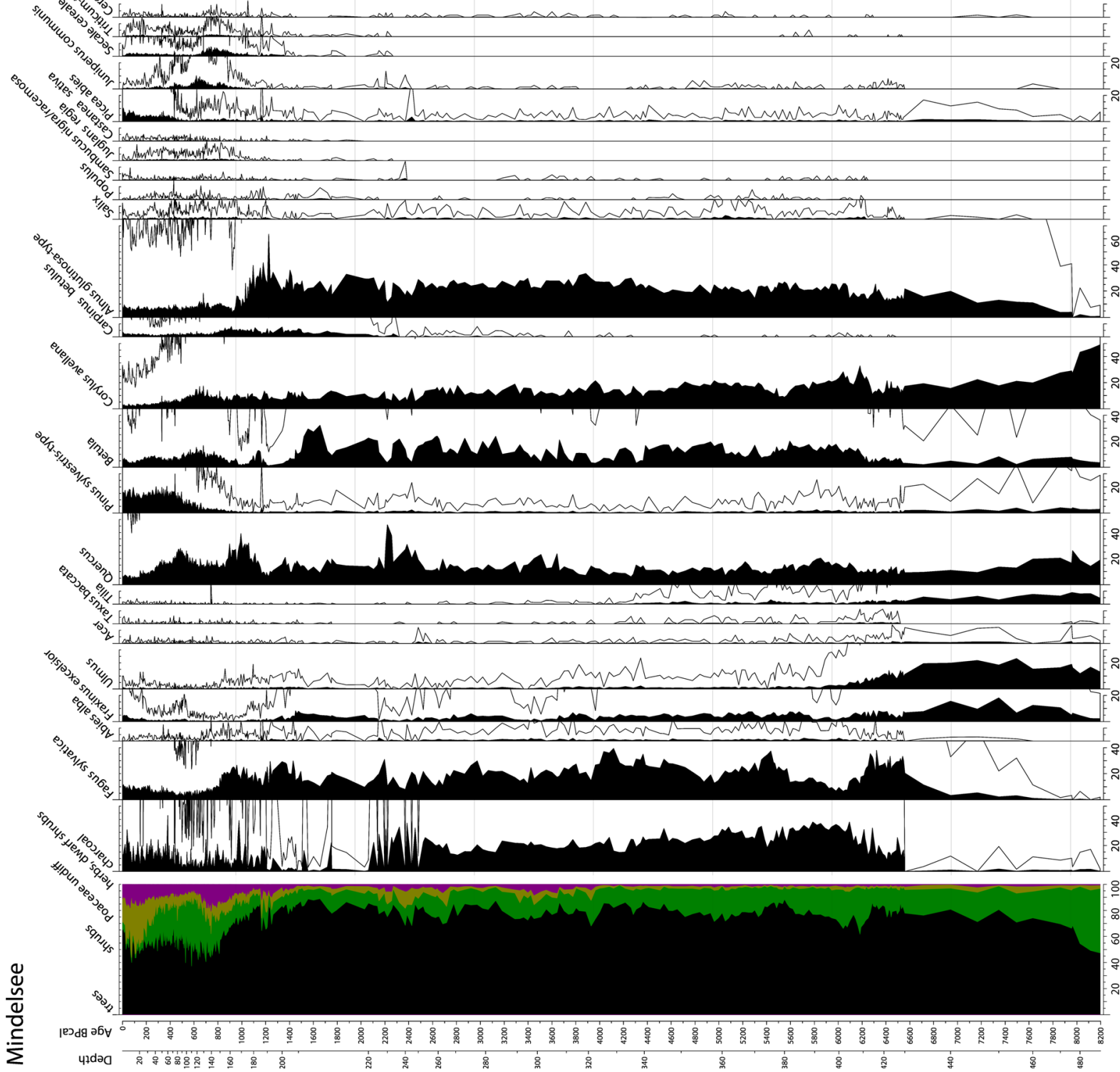

